\title{
The burden of disease attributable to nutrition in Europe
}

\author{
Joceline Pomerleau ${ }^{1, *}$, Martin McKee ${ }^{1}$, Tim Lobstein ${ }^{2}$ and Cécile Knai ${ }^{3}$ \\ ${ }^{1}$ European Centre on Health of Societies in Transition, London School of Hygiene and Tropical Medicine, \\ Keppel Street, London WC1E 7HT, UK: ${ }^{2}$ Food Commission, 94 White Lion Street, London N1 9PF, UK: \\ ${ }^{3}$ Nutrition and Food Security, WHO Regional Office for Europe, Scherfigsvej 8, 2100 Copenhagen, Denmark
}

Submitted 5 June 2002: Accepted 17 December 2002

\begin{abstract}
Objective: This review examines the extent to which differences in nutrition could explain the diversity of health in Europe and how dietary patterns might contribute to the overall burden of disease in the region.

Setting: Europe.

Design: Between-country variations and time trends in dietary and health patterns in Europe are described, taking into account recent evidence on east-west mortality differentials. Existing information on the contribution of dietary factors to the overall burden of disease in Europe and to the burden of cardiovascular diseases and cancer is then reviewed, including a discussion of the methodological challenges that face those seeking to quantify this burden accurately.

Results: While evidence from ecological data have long suggested that variations in health patterns in Europe may be at least partly attributed to differences in dietary intake, recent research into the major risks to disease, disability and death is confirming the importance of poor nutrition to major health problems and overall disease burden in Europe. Findings from the Global Burden of Disease 2000 study suggest that $4.4 \%$ of the overall burden of disease in the region could be attributed to low fruit and vegetable intake, and $7.8 \%$ to overweight and obesity.

Conclusions: The burden of disease attributed to poor nutrition in Europe appears to be substantial and probably underestimated. However, better quantification of the contribution of nutrition to the region's burden of disease awaits further research to assess the dietary intake of Europeans and to explore the relationship between nutritional factors and health outcomes in diverse parts of Europe.
\end{abstract}

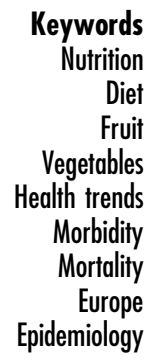

Across Europe, increasing numbers of policy-makers are exploring inter-sectoral strategies to improve the health of populations. To do so, they require a detailed understanding of the population burden of disease and its determinants. The seminal study on the Global Burden of Disease (GBD), undertaken in the early $1990 \mathrm{~s}^{1}$ and recently updated to provide estimates for the year $2000^{2}$, makes a major contribution to this process, identifying and quantifying the numbers of years lost due to premature death and the numbers of years of disability attributable to major determinants of disease in all regions of the world. The GBD study introduced the concept of 'disabilityadjusted life year' (DALY), a measure incorporating both loss of life years and impaired quality of life.

Yet despite this and other efforts to measure disease burden in different parts of the world, the share of the disease burden in Europe that can be attributed to nutrition has not yet been quantified. It is, however, apparent that this contribution is likely to be substantial. The importance of a healthy and varied diet in the maintenance of health and prevention of disease is widely accepted $^{3-5}$ and emerging research indicates that a substantial proportion of the variation in mortality rates among the countries of Europe can be attributed to differences in eating patterns ${ }^{6}$. This paper reviews the extent to which differences in nutrition might explain the diversity of health in Europe, the existing evidence on the burden of disease that can be attributed to nutrition in Europe, and the challenges that face those seeking to quantify this burden more accurately.

\section{Changing patterns of health in Europe: evidence for the role of nutrition}

A combination of fortuitous circumstances enables Europe to make a unique contribution to understanding the determinants of population health and disease. These are: first, its large geographical and cultural diversity, giving rise to populations with exposures to very different levels of dietary components; and second, the high quality of data on mortality makes it possible to assess the variation in patterns of disease and to link risk factors and outcomes in ways that are impossible in many other parts of the world ${ }^{7}$. 


\section{Between-country variations and time trends in bealtb and diet}

Life expectancy at birth differs greatly among the different parts of Europe, reflecting different rates of leading causes of deaths (Table 1) 8,9 . Cardiovascular diseases and cancers, known for their association with poor dietary habits (including high saturated fat and low fruit and vegetable intakes) $)^{3,10}$, are the most important killers in all parts of Europe, accounting for two-thirds of all deaths on average. However, between-country variations are dramatic. For example, mortality rates for ischaemic heart disease (IHD) range from approximately 20 to over 570 per 100000 population and rates for malignant neoplasms, excluding cancers of the lung, bronchus and trachea, from about 76 to 216 per 100000 population?

The observation that life expectancy in some countries of southern Europe such as Spain and Greece is longer than would be predicted from their level of economic development ${ }^{9}$ has led to the emergence of the concept of the 'Mediterranean diet', rich in fruits and vegetables and monounsaturated fats (mainly in the form of olive oil) ${ }^{11,12}$. There is growing research suggesting that this diet can reduce the risk of IHD and some types of cancer, and that populations that have not traditionally followed such a diet could benefit from doing so ${ }^{13-16}$. One of the most striking differences in food availability between southern and other parts of Europe is that fruit and vegetable availability is much higher in the south of Europe than it is in all other parts, especially in countries of central and eastern Europe (CCEE) and the former Soviet Union (FSU) (Fig. 1) ${ }^{17}$. Thus, fruit and vegetable availability in Spain, for example, is about four times higher than in Kazakstan. Within Europe, this diversity is strongly correlated with mortality from various diseases, including IHD (Fig. 2) ${ }^{9}$.

Further insights into the role of nutrition in health in Europe are offered by observations of how patterns of both diet and health are changing over time ${ }^{9,17-19}$. Over recent decades there have been steady and substantial declines in overall mortality for both sexes in all western European countries, even though appreciable geographic differences persist ${ }^{20}$. These favourable trends reflect in particular a decline in coronary heart disease (CHD) mortality in most western countries, as well as a fall in cerebrovascular disease $^{21}$. One major factor underlying these improvements is the decrease in smoking rates in men $^{22}$, the effect of which is apparent after some years. Other potential factors of influence include physical exercise and improved control of hypertension and medical care, as well as better nutrition ${ }^{23}$. Indeed, ecological observations suggest that reductions in per capita availability of dietary fats, increases in the availability of fruit and vegetables and increased cereal consumption in many northern and western European countries have accompanied the changes observed in mortality due to cardiovascular disease ${ }^{9,17}$. In southern Europe, fruit and vegetable intakes have not shown the same increases, although they began at a much higher baseline, and there has been a noticeable increase in

Table 1 Estimated relative causes of disability-adjusted life years (DALYs) lost in Europe for the year 2001

\begin{tabular}{lc}
\hline & $\begin{array}{c}\text { Contribution } \\
\text { Disorder }\end{array}$ \\
\hline Communicable, maternal, perinatal, and nutritional conditions & total loss of DALYs (\%) \\
Infectious and parasitic diseases & 9.7 \\
Respiratory infections & 3.9 \\
Maternal conditions & 2.4 \\
Perinatal conditions & 0.5 \\
Nutritional deficiencies & 1.9 \\
Non-communicable diseases & 1.0 \\
Malignant neoplasms & 76.6 \\
Other neoplasms & 11.5 \\
Diabetes mellitus & 0.2 \\
Endocrine disorders & 1.5 \\
Neuropsychiatric conditions & 0.7 \\
Sense organ disorders & 20.2 \\
Cardiovascular diseases & 3.4 \\
Respiratory diseases & 22.6 \\
Digestive diseases & 4.7 \\
Genitourinary diseases & 4.7 \\
Skin diseases & 1.2 \\
Musculoskeletal diseases & 0.2 \\
Congenital anomalies & 3.8 \\
Oral conditions & 1.3 \\
Injuries & 0.7 \\
Unintentional injuries & 13.7 \\
Intentional injuries & 9.3 \\
Total & 4.4 \\
\hline
\end{tabular}

Source: World Health Organization ${ }^{2}$. 


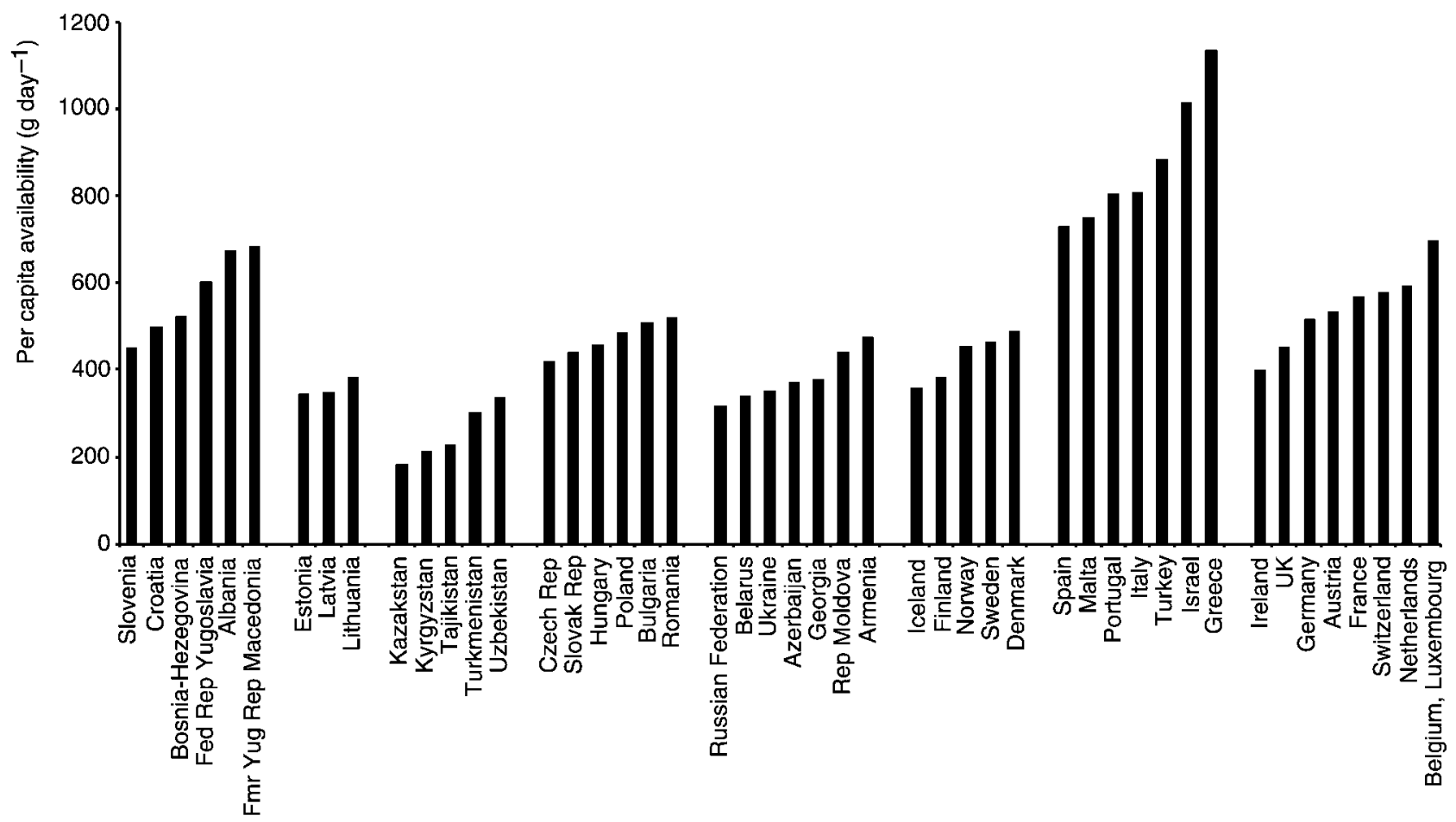

Fig. 1 Fruit and vegetable availability by sub-region and country in 1996-98. Source: Food and Agriculture Organization ${ }^{17}$

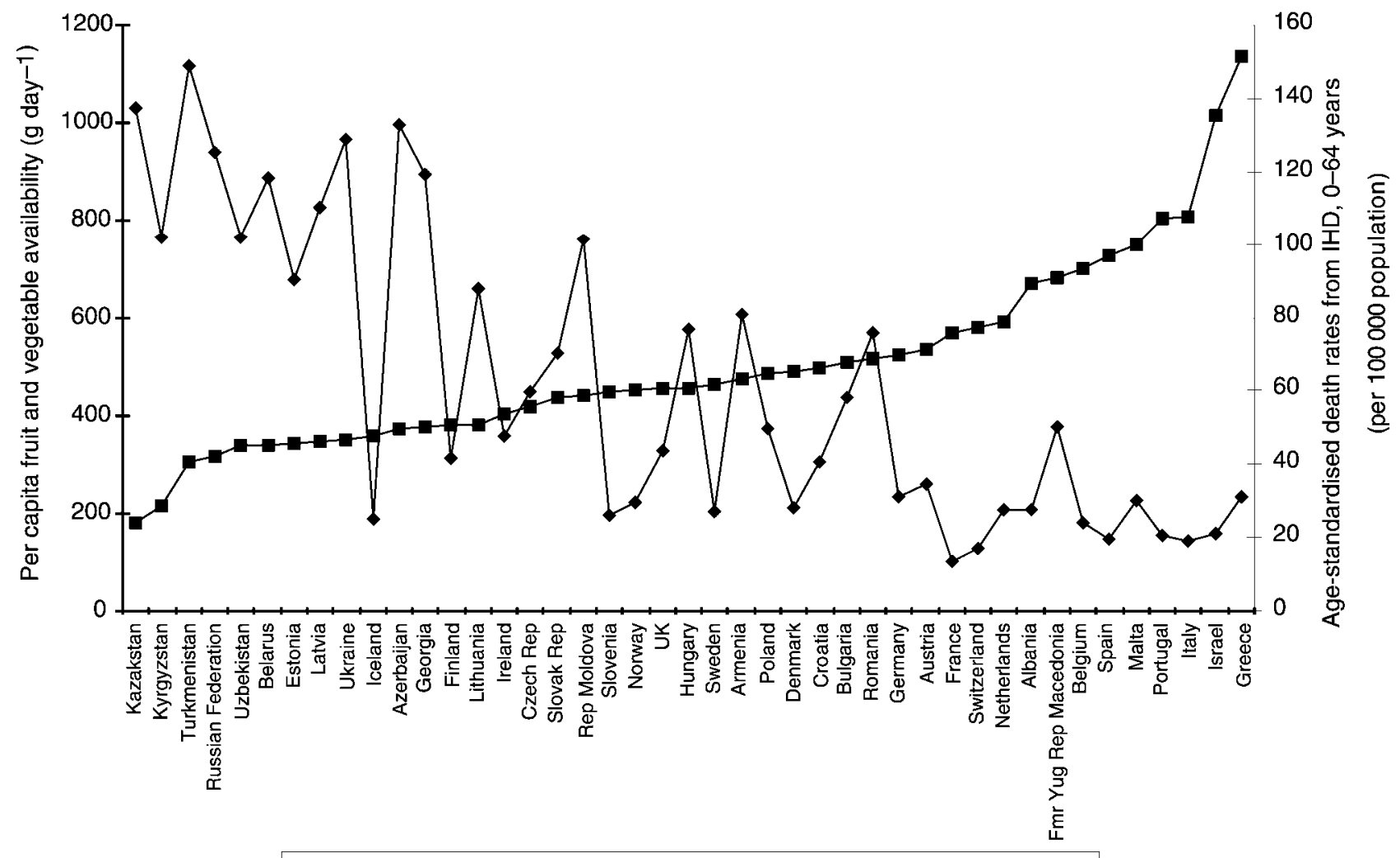

Fig. 2 Relationship between per capita availability of fruits and vegetables and age-standardised death rates from ischaemic heart disease (IHD) before age 65 years, per 100000 population. Source: World Health Organization Health for All Database ${ }^{9}$ and Food and Agriculture Organization ${ }^{17}$ 
saturated and/or polyunsaturated fats and a decrease in the consumption of cereals.

In contrast to the trends observed in western Europe, the CCEE and FSU countries experienced dramatic rises in overall mortality and deaths from cardiovascular diseases and a decrease in life expectancy in the early 1990s. By the late $1990 \mathrm{~s}$, overall mortality was still 1.5 to 2 times higher for males and 1.5 to 1.8 times higher for females in CCEE and FSU, respectively, compared with western Europe, and the difference in life expectancy at birth between the 'best' and 'worst' European countries was more than 10 years for both sexes? ${ }^{9}$. This sharp divide in life expectancy and mortality rates between western Europe and the former Socialist countries of Europe, as well as the rapid socio-economic and political changes that have taken place in some of the latter since 1990, provide further insights into the possible impact of diet on disease burden in the region. This is particularly relevant since the observed gap in mortality is due largely to chronic diseases in adulthood ${ }^{24}$, with these diseases also explaining much of the increasing diversity among individual countries in the region.

The east-west mortality differential in Europe is clearly multi-factorial, with influences acting directly and indirectly. Underlying factors include socio-economic and psychosocial changes. Tobacco, alcohol and deficiencies of medical care act more directly ${ }^{24}$. However, in addition to these factors, there is growing evidence supporting a central role for diet in explaining mortality in those countries where food insecurity and inadequate access to a variety of healthy, safe foods have changed during the last decade ${ }^{25}$. There have been improvements in some countries but a deterioration in others where there has been increasing impoverishment, with a larger share of disposable income spent on foods ${ }^{26,27}$.

The precise mechanisms involved in this mortality differential are, however, less certain. Bobak et al. propose that fats and antioxidants may be the most likely dietary contributors to the geographical differences in mortality in Europe $^{28}$. However, the consumption of animal fat reported to the Food and Agriculture Organization by member states does not show dramatic differences between eastern and western Europe ${ }^{17}$. Similarly, plasma cholesterol concentrations recorded in MONICA (Monitoring Trends and Determinants in Cardiovascular Disease) centres in the 1980s did not show a large difference between central and eastern Europe and western Europe $^{29}$. In contrast, studies exploring ecological differences in antioxidant intake or status among European countries are consistent with the hypothesis that low intakes of antioxidants (these coming mostly from fruit and vegetables) are related to major health problems such as cardiovascular diseases (antioxidant hypothesis $)^{30,31}$. For example, plasma concentrations of retinol and tocopherol and dietary intake of vitamin $\mathrm{C}$ are low in Hungary and Poland compared with those in the western European population ${ }^{32}$. Plasma concentrations of $\beta$ - and $\alpha$-carotene and lycopene are lower in the Czech Republic than in Bavaria ${ }^{28}$. Levels of $\beta$-carotene, lycopene and $\gamma$-tocopherol (lipid-adjusted values) are lower in Lithuania than in Sweden ${ }^{33}$. However, it is likely that other, less well understood components of food will also differ, with important consequences for health.

Gjonca and Bobak draw attention to the paradox of high adult life expectancy in Albania despite its being the poorest country in Europe ${ }^{34}$. In 1990, the age-standardised mortality for IHD in males aged 0-64 years was 41 per 100000 in Albania, less than half of the rate in the UK and similar to that in Italy. A detailed analysis of the geographical distribution of mortality within Albania showed that it was lowest in the south-west of the country where most of the olive oil, fruits and vegetables are produced and consumed. Albania provided a unique opportunity to study this relationship because of the almost complete absence of motorised transport, limiting inter-regional food distribution, combined with highquality mortality data. The authors argue that this paradox of high adult life expectancy in the lowest-income eastern European country can be most plausibly explained by diet - namely, a low consumption of total energy, meat and milk products, but high consumption of fruit, vegetables and carbohydrates. It is likely that the situation will have changed rapidly following the political transition ${ }^{35}$ but data problems due to unrecorded migration mean that it may be some time before this can be reassessed.

Zatonski et al. investigated the reasons for the decline in deaths attributed to IHD in Poland since 1991, following two decades of rising rates ${ }^{36}$. Having considered the potential role of changes in food availability, smoking, alcohol consumption, stress and medical care, the authors attributed the substantial decline in mortality from diseases of the circulatory system in middle-aged men and women to changes in the type of dietary fat consumed and to an increased supply of fresh fruit and vegetables.

Such findings from ecological studies, although criticised for their limitations ${ }^{37}$, have provided an important stimulus to the accumulating epidemiological research reporting that diets high in fruits and vegetables reduce the risk of major diseases such as cardiovascular diseases and certain cancers $5,38-40$.

\section{Measuring the burden of disease in Europe}

Results from the recent GBD 2000 study indicated that about $13.7 \%$ of years lost to disability and death in the World Health Organization (WHO) European region are caused by injuries, $9.7 \%$ by infectious and parasitic diseases, respiratory infections, maternal and perinatal conditions and nutritional deficiencies, and the remaining $76.6 \%$ by non-communicable diseases led by heart disease, cancers and neuropsychiatric illness - thus, the bulk of the disability and premature death is due to 
non-communicable diseases (Table 1). Together, cardiovascular diseases, cancers and diabetes account for more than two-fifths of the total DALYs lost $(20.2 \%, 11.7 \%$ and $1.5 \%$, respectively). Similar results were obtained in a national burden of disease analysis for The Netherlands ${ }^{41}$.

\section{Contribution of nutritional factors to the overall burden of diseases in Europe}

The first attempt to estimate the burden of disease attributed to nutrition in Europe was made in Sweden in 1997. The National Institute of Public Health was then commissioned to assess the burden of disease attributable to different factors in the European Union (EU), including $\operatorname{diet}^{42}$. It was estimated that diet-related factors directly contributed almost $8.3 \%$ of the estimated burden of disease, half of this due to low fruit and vegetable intake (Table 2). Physical exercise made a further contribution of $1.4 \%$, to give a total of $9.7 \%$ lost to poor nutrition, excess weight and physical inactivity. In comparison, the Swedish study estimated that tobacco smoking accounted for $9 \%$ of the burden of disease in the EU. Improved diet could thus be the most important contributor to reducing the burden of disease in developed economies. In fact, this study may even underestimate the importance of nutrition since dietary factors probably interact with other risk factors. For example, high intakes of fruit and vegetables appear to reduce the risk of lung cancer among smokers ${ }^{43}$ (although even among those with the highest intakes smoking greatly increases the probability of developing lung cancer) and other dietary components may moderate the impact of alcohol abuse.

The beneficial role of fruit and vegetables has attracted much attention in public health nutrition during the last decade. Indeed, the consistent pattern of findings suggesting the role of a diet rich in fruit and vegetables in the prevention of major health problems has led several national and international bodies to advocate an increase in individual intake to at least 400 grams a day ${ }^{3,5,44}$. The EU burden of disease study suggested that $3.5 \%$ of the overall

Table 2 Contribution of different factors to the burden of disease in the European Union

\begin{tabular}{lc}
\hline Causal factor & $\begin{array}{c}\text { Contribution to overall } \\
\text { burden of disease (\%) }\end{array}$ \\
\hline Tobacco smoking & 9.0 \\
Alcohol consumption & 8.4 \\
Overweight* & 3.7 \\
Occupational risks & 3.6 \\
Low fruit and vegetable consumption* & 3.5 \\
Relative poverty & 3.1 \\
Unemployment & 2.9 \\
Illicit drugs & 2.4 \\
Physical inactivity & 1.4 \\
Diet high in saturated fat & 1.1 \\
Outdoor air pollution & 0.2 \\
\hline
\end{tabular}

Source: National Institute of Public Health ${ }^{42}$.

${ }^{*}$ Diet-related factors. disease burden in the EU was attributable to a low fruit and vegetable intake and another recent study reported that approximately 23000 deaths from CHD and major cancers before the age of 65 years could be prevented annually in the EU and three countries in the process of acceding to it if fruit and vegetable consumption was to increase substantially ${ }^{45}$. In Australia and New Zealand similar findings were reported ${ }^{46-48}$, with approximately 3\% (2.8\% in Australia and $2-4 \%$ in New Zealand) of the burden of disease attributed to a low fruit and vegetable intake. The Australian study also reported that about $10 \%$ of all cancers could be attributable to an insufficient intake of fruit and vegetables.

The most recent evidence for the importance of nutritional factors in preventing disability and death in Europe comes from the GBD 2000 study $^{2}$. GBD findings suggest that $4.4 \%$ of the overall burden of disease in the region could be attributed to low fruit and vegetable intake and $7.8 \%$ to overweight and obesity. When the countries of the region are divided into those with differing levels of child (under 5 years) and adult (15- to 59-year-old male) mortality, sub-regional differences emerge. While the proportion of the overall disease burden attributed to low fruit and vegetable intake is $2.2 \%$ in countries with very low child and adult mortality and $3.3 \%$ in countries with low child and adult mortality, it reaches $6.9 \%$ in countries with low child mortality but high adult mortality (mostly former Communist countries). For overweight and obesity, these proportions are 6.9\%, $7.3 \%$ and $8.9 \%$, respectively. The potential public health impact of these findings is just starting to be evaluated.

\section{Contribution of diet to the burden of cardiovascular diseases and cancers}

As noted above, cardiovascular diseases and cancers are the leading causes of death and of DALYs lost in Europe. Conservative estimates suggest that around one-third of cardiovascular diseases could be related to inadequate diets, though the need for more research is widely acknowledged $^{49}$. A recent report by the World Cancer Research Fund and the American Cancer Institute estimated that better dietary intake, together with the maintenance of physical activity and adequate body mass, could help reduce cancer incidence by $30-40 \%{ }^{5}$. A widely cited estimate of the diet-related burden of cancer was made by Doll and Peto ${ }^{50}$. They estimated that about 35\% of all cancer deaths in the USA were attributable to diet (excluding alcohol), with a range of plausible estimates of between $10 \%$ and $70 \%$. It was later proposed that the evidence available up to the early 1990s involving diet with cancer had become stronger, and a narrower range of 20-60\% was proposed ${ }^{51}$.

Identifying the components of diet that have the largest influence on cardiovascular diseases and cancer has been and still is a major challenge. Many older clinical and epidemiological investigations focused on the amount 
of dietary fat consumed ${ }^{52}$, but more recently the potential impact of types of fats, including the reduction of trans-fatty acids ${ }^{53}$ or animal fats ${ }^{54}$, was also examined. It was suggested, for example, that replacing six percentage units of energy intake from predominantly animal fats to monounsaturated fats could potentially reduce cardiovascular diseases by $6-8 \%$.

Other dietary factors have also been related to the risk of cardiovascular disease and cancer. Excess energy intake and alcohol are risk factors for certain cancers (mouth, pharynx, larynx, oesophagus and liver), while a diet rich in fruit and vegetables could help protect against heart disease and cancers of the mouth, pharynx, digestive tract and lung $5,40,55,56$. Results from the GBD 2000 study suggest that, in developed countries, approximately $28 \%$ and $18 \%$ of the burden of disease due respectively to IHD and ischaemic stroke could be attributed to low fruit and vegetable intake ${ }^{2}$. For cancers of the oesophagus, stomach, colon/rectum and trachea/bronchus/lung, these proportions become $17 \%$, $18 \%, 2 \%$ and $11 \%$, respectively. Deficiencies of substances such as vitamin A, other antioxidant vitamins and certain non-nutrient components of fruits and vegetables have also been associated with an increased risk of both cardiovascular diseases and cancer in some studies. However, more research is needed to clarify the relationships already observed and to identify which components of fruit and vegetables may provide a protective effect ${ }^{5,40,57}$.

\section{Update of the GBD study: methodological considerations}

The GBD study update for 2000, from which selected summary results have been presented above, is a major undertaking $^{2}$. It estimated, for 26 different risk factors including fruit and vegetable consumption and high body mass index (overweight and obesity) - and for 14 subregions, analysed by age and sex, the attributable burden of disease and injury for the year 2000 and the avoidable burden of disease and injury in 2001, 2005, 2010, 2020 and 2030.

The core methodology used in the GBD study is the estimation of attributable fractions, defined as the percentage reduction in disability and death that would occur if exposure to a given risk factor were reduced to a defined counterfactual, in many cases zero exposure, with all other factors remaining the same ${ }^{3,58}$. Hence, the attributable burden of disease is defined as the difference between the currently observed burden and the burden that would be observed if the distribution of exposure was at a level that would yield the theoretical lowest population risk. The GBD results will thus describe the proportion of cases of a disease that are prevented if a certain risk factor is eliminated ${ }^{58,59}$.

The estimation of the attributable and avoidable burden of disease requires two main sources of data stratified by age, sex and region ${ }^{60}$. First, risk factor levels, including current distributions of exposure to a certain risk factor and counterfactuals based on the risk factor level that would yield the lowest overall population risk; and, second, risk factor-disease relationships, i.e. the characterisation of the relationship between risk factors and disease for each disease or injury outcome that is caused by a defined risk factor. When assessing the impact of low fruit and vegetable intake, estimates of disease burden are thus dependent on the availability, reliability, validity and generalisability of data on fruit and vegetable intake, and on current epidemiological knowledge of the association between fruit and vegetable intake and health problems. These are subject to several sources of uncertainty, as described below ${ }^{61}$.

Measurement of dietary exposure and the choice of a counterfactual are problematic. First, although differences in dietary patterns among regions and countries are acknowledged, assessing the level of these differences represents a major challenge. Nationally representative surveys of dietary intake are available in only a few countries and the diversity of the methods used makes comparisons difficult ${ }^{62}$. This is a greater concern in Africa, Central and South America and major parts of Asia than in Europe, where data are available for most EU countries, but there is a general lack of information from countries of the FSU and CCEE. Second, when the objective of the survey is to measure individuals' actual food and nutrient intakes, the validity of the data is highly influenced by the ability and willingness of the respondents to provide accurate information on their intake, or the potential for the procedure involved in measuring dietary intake to lead to changes in behaviour ${ }^{63,64}$. Any error in the measurement of dietary intake means that the strength of true associations is likely to be reduced. Third, the definition of the exposure as 'fruit and vegetables' introduces a substantial amount of non-specificity with the resultant potential attenuation of underlying causal relations. This is especially important across food cultures with substantial differences in the makeup of foods that constitute the fruit and vegetable group, but also applies even within cultures because of differences in food composition. Fourth, seasons are also known to influence the amounts and variety of fruit and vegetables consumed. Evidence is emerging to link seasonality of consumption of fresh fruit and vegetables to the pattern of cardiovascular disease mortality in some countries ${ }^{65}$. It is possible that the consequences for disease of an annual cycle of seasonal excesses and out-of-season shortages (as in the less economically developed countries of the FSU) may be quite different to the effects of consuming a similar annual level where counter-seasonal supplies ensure that there is no period of very low consumption (as in the affluent countries of north-west Europe). Finally, the choice of a counterfactual is fraught with difficulty. Evidence suggests that those in the highest categories of fruit and 
vegetable consumption have lower risk compared with those in the lowest consumption categories. However, it is not yet clear whether there is a threshold effect for fruit and vegetable consumption nor is it clear whether the same threshold would apply to all protective effects ${ }^{66}$.

Obtaining estimates of the magnitude of the association between fruit and vegetable consumption and diseases is becoming easier due to the increasing number of epidemiological studies and the relative consistency of their findings $5,40,67$. However, there remains uncertainty with regard to the precise constituents (or combination of constituents) of fruits and vegetables that would confer a protective effect and the many complex biological pathways and interactions that lead to common diseases. Different studies have suggested that flavonoids, carotenoids, vitamin C, folic acid and fibre could play a protective role. However, it must be kept in mind that studies based on single food constituents may underestimate the effects of exposures to foods, which are chemically complex. Also, single constituents can be a marker for other active constituents (as the conflicting results between observational studies and trials have suggested for $\beta$-carotene) ${ }^{68,69}$ or even for a combination of constituents that is responsible for the protective effect. Until these mechanisms are better understood, it will not be possible to determine, with any certainty, what precise role specific components of fruit and vegetables might play. What can be said with some confidence is that there is a wide variety of substances within fruit and vegetables that appear to play a role, but it is unlikely that any single compound will capture the benefits that seem to arise from a varied diet that is rich in fruit and vegetables. Another source of uncertainty in assessing risk factor-disease relationships in epidemiological studies is the inherent difficulty of measuring usual dietary intake at the individual level as described above ${ }^{70}$. In addition, most studies to date have been conducted in only a few countries, mostly of 'Western' culture (EU countries, USA or Japan), and with limited age groups. Therefore, estimates of relative risks may not be generalisable to all populations, even within Europe. This concern about generalisability has grown following the emergence of evidence that what had been thought to be well established relationships between lipids and disease, based on research in Western populations, do not necessarily apply in eastern Europe ${ }^{71}$. A further factor to be considered is the fact that if fruit and vegetables are truly protective, then they are protective against some factor. Thus, any effect will only be seen when this other factor is also present. Another major source of uncertainty refers to the fact that residual confounding and measurement error in the assessment of potential confounders are real possibilities in observational studies of the relationship between fruit and vegetable intake and health outcomes ${ }^{72}$.

Finally, many important diseases involve a complex interaction between genetic susceptibility, programming in early childhood and interactions between different risk factors. In particular, understanding patterns of cardiovascular disease must take account of the role of exposure to tobacco smoke, with its potent effects on various aspects of vascular and platelet function, although this remains a challenge for the comparative risk assessment method used in the GBD programme.

\section{Conclusion}

Quantifying the overall burden of disease is a dynamic process, with several countries undertaking independent reviews of the attributable causes of disease burden in their population and with WHO having just released its new round of GBD findings. Until recently, the impact of nutrition on disease burden was given little attention but this is now changing. Indeed, the influence of diet throughout the life cycle is widely recognised, and the major contribution of poor nutrition to major health problems and the resulting costs in Europe are increasingly being quantified ${ }^{73}$. As we have discussed in this paper, variations in mortality rates in Europe can, at least partly, be attributed to differences in dietary intake. In addition, emerging evidence suggests that the contribution of poor nutrition to major health problems and to the overall burden of disease in Europe is substantial and probably underestimated. However, better quantification of the contribution of nutrition to the overall burden of disease in Europe will require further research to assess the nutritional status and dietary intake of Europeans and to explore the relationship between nutritional factors and health outcomes in diverse parts of Europe, such as the ongoing EPIC (European Prospective Investigation into Cancer and Nutrition) project ${ }^{74}$. Finally, several initiatives promoting the development of national and regional food and nutrition policies are appearing on the European public health agenda ${ }^{6,75,76}$. They can be expected to have a positive impact on nutritional health, and thus disease burden, in Europe.

\section{Acknowledgements}

This work was funded by a grant from the Nutrition Programme of the European Regional Office of the World Health Organization (WHO). However, WHO can accept no responsibility for the views expressed. We are grateful to Dr Aileen Robertson whose vision and support made this work possible.

\section{References}

1 Murray CJ, Lopez AD. Global mortality, disability, and the contribution of risk factors: Global Burden of Disease Study. Lancet 1997; 349: 1436-42.

2 World Health Organization (WHO). The World Health Report 2002. Reducing Risks, Promoting Healthy Life. Geneva: WHO, 2002. 
3 World Health Organization (WHO). Diet, Nutrition and The Prevention of Chronic Diseases. Technical Report Series No. 797. Geneva: WHO, 1990.

4 European Heart Network. Food, Nutrition and Cardiovascular Disease Prevention in Europe. Brussels: European Heart Network, 1998.

5 World Cancer Research Fund/American Institute for Cancer Research (AICR). Food, Nutrition and The Prevention of Cancer: A Global Perspective. Washington, DC: AICR, 1997.

6 Nutrition and Diet for Healthy Lifestyles in Europe: Science and Policy Implications. Proceedings of the European Conference, Crete, Greece, 18-20 May 2000. In: Kafatos AG, Codrington CA, eds. Eurodiet Report and Proceedings [special issue]. Public Health Nutrition 2001; 4(2A): $337-436$

7 McKee M, Jacobson B. Public health in Europe. Lancet 2000; 356: $665-70$.

8 World Health Organization (WHO) Regional Office for Europe. Health in Europe 1997. WHO Regional Publications, European Series No. 83. Copenhagen: WHO Regional Office for Europe, 1998.

9 World Health Organization (WHO) Regional Office for Europe. Health for All Database. Copenhagen: WHO Regional Office for Europe, 2002.

10 James WPT, Ferro-Luzzi A, Isaksson B, Szostak WB. Healthy Nutrition. Preventing Nutrition-related Diseases in Europe. Copenhagen: World Health Organization Regional Office for Europe, 1988

11 Keys A. Seven Countries: A Multivariate Analysis of Death and Coronary Heart Disease. Cambridge, MA: Harvard University Press, 1980.

12 Willett WC, Sacks F, Trichopoulou A, Drescher G, Ferro-Luzzi A, Helsing E, et al. Mediterranean diet pyramid: a cultural model for healthy eating. American Journal of Clinical Nutrition 1995; 61(Suppl.): 1402S-6.

13 de-Lorgeril M, Renaud S, Mamelle N, Salen P, Martin JL, Monjaud I, et al. Mediterranean alpha-linolenic acid-rich diet in secondary prevention of coronary heart disease. Lancet 1994; 343: 1454-9.

14 Trichopoulou A, Lagiou P. Healthy traditional Mediterranean diet: an expression of culture, history, and lifestyle. Nutrition Reviews 1997; 55: 383-9.

15 Kouris-Blazos A, Gnardellis C, Wahlqvist ML, Trichopoulos D, Lukito W, Trichopoulou A. Are the advantages of the Mediterranean diet transferable to other populations? A cohort study in Melbourne, Australia. British Journal of Nutrition 1999; 82: 57-61.

16 Assman G, Sacks F, Awad AB, Bonanome A, Booyse FM, Carmena $\mathrm{R}$, et al. Dietary fat, the Mediterranean diet and lifelong good health. 2000 International Conference on the Mediterranean Diet. 2000 Consensus Statement [online]. London: Royal College of Physicians, January 2000. Available at http://www.chd-taskforce.de/2000 consensusstatement/index_e.html. Accessed 25 September 2002.

17 Food and Agriculture Organization (FAO). FAOSTAT Database [online]. Rome: FAO, 2001. Available at http:// www.apps.fao.org/1. Accessed 1 December 2001.

18 Lobstein T, Longfield J. Improving Diet and Health through European Union Food Policies. London: Health Education Authority, 1999.

19 Lang T. Food and nutrition. In: Weil O, McKee M, Brodin M, Oberlé D, eds. Priorities for Public Health Action in Europe. Brussels: European Commission, 1999; 138-56.

20 La Vecchia C, Levi F, Lucchini F, Negri E. Trends in mortality from major diseases in Europe, 1980-1993. European Journal of Epidemiology 1998; 14: 1-8.

21 Sans S, Kesteloot H, Kromhout D on behalf of the Task Force. The burden of cardiovascular diseases mortality in Europe. Task Force of the European Society of Cardiology on Cardiovascular Mortality and Morbidity Statistics in Europe. European Heart Journal 1997; 18: 1231-48.

22 British Heart Foundation Health Promotion Research Group. European Cardiovascular Disease Statistics [online]. Oxford: British Heart Foundation. Available at http://www.dphpc. ox.ac.uk/bhfhprg/stats/2000/europe/introduction.html. Accessed 25 September 2002.

23 Levi F, Lucchini F, Negri E, La Vecchia C. Trends in mortality from cardiovascular and cerebrovascular diseases in Europe and other areas of the world. Heart 2002; 88: 119-24.

24 Bobak M, Marmot M. East-west mortality divide and its potential explanations: proposed research agenda. British Medical Journal 1996; 312: 421-5.

25 Marmot M, Wilkinson RG. Social Determinants of Health Oxford: Oxford University Press, 1999.

26 Roks C, Galloway R, Brown L. Prospects for Improving the Nutrition Situation in Eastern Europe and Central Asia. Washington, DC: World Bank, 2000

27 Food and Agriculture Organization (FAO). The State of Food Insecurity in the World. Rome: FAO, 1999.

28 Bobak M, Hense HW, Kark J, Kuch B, Vojtisek P, Sinnreich R, et al. An ecological study of determinants of coronary heart disease rates: a comparison of Czech, Bavarian and Israeli men. International Journal of Epidemiology 1999; 28: 437-44.

29 WHO MONICA Project Principal Investigators. The World Health Organization MONICA Project (monitoring trends and determinants in cardiovascular disease): a major international collaboration. Journal of Clinical Epidemiology 1988; 41: 105-14.

30 Witzum JL. The oxidation hypothesis of atherosclerosis Lancet 1994; 344: 793-5.

31 Jha $\mathrm{P}$, Flather $\mathrm{M}$, Lonn E, Farkouh $\mathrm{M}$, Yusuf $\mathrm{S}$. The antioxidant vitamins and cardiovascular disease. A critical review of epidemiologic and clinical trial data. Annals of Internal Medicine 1995; 123: 860-72.

32 EURONUT-SENECA. Nutrition and the elderly in Europe. European Journal of Clinical Nutrition 1991; 45(Suppl. 3) $1-196$.

33 Kristenson M, Ziedén B, Kucinskienë Z, Abaravicius A, Razinkovienë L, Schäfer Elinder L, et al. Antioxidant state and mortality from coronary heart disease in Lithuanian and Swedish men: concomitant cross sectional study of men aged 50. British Medical Journal 1997; 314: 629-33.

34 Gjonca A, Bobak M. Albanian paradox, another example of protective effect of Mediterranean lifestyle? Lancet 1997; 350: $1815-7$.

35 Shapo L, Coker R, McKee M. Tracking diabetes in Albania: a natural experiment on the impact of modernisation on health. Diabetic Medicine 2002; 19: 87-8.

36 Zatonski WA, McMichael AJ, Powles JW. Ecological study of reasons for sharp decline in mortality from ischaemic heart disease in Poland since 1991. British Medical Journal 1998; 316: $1047-51$.

37 Ebrahim S, Davey Smith G. Ecological studies are a poor means of testing aetiological hypotheses. British Medical Journal 1998; 317: 678.

38 Klerk M, Jansen MCJF, van't Veer P, Kok FJ. Fruits and Vegetables in Chronic Disease Prevention. Part II: Update and Extension (literature up to early 1998). Wageningen: Wageningen Agricultural University, 1998.

39 Van't Veer P, Jansen MCJF, Klerk M, Kok FJ. Fruits and vegetables in the prevention of cancer and cardiovascular disease. Public Health Nutrition 2000; 3: 103-7.

40 Ness AR, Powles JW. Fruit and vegetables, and cardiovascular disease: a review. International Journal of Epidemiology 1997; 26: 1-13. 
41 Melse JM, Essink-Bot M-L, Kramers PGN, Hoeymans N. A national burden of disease calculation: Dutch disabilityadjusted life-years. American Journal of Public Health 2000; 90: $1241-7$.

42 National Institute of Public Health (NIPH). Determinants of the Burden of Disease in the EU. Stockholm: NIPH, 1997.

43 Yong LC, Brown CC, Schatzkin A, Dresser CM, Slesinski MJ, Cox CS, et al. Intake of vitamins E, C, and A and risk of lung cancer. The NHANES I epidemiologic followup study. First National Health and Nutrition Examination Survey. American Journal of Epidemiology 1997; 146: 231-43.

44 Committee on Diet and Health. Diet and Health: Implications for Reducing Chronic Disease Risk. Washington, DC: National Academy Press, 1989.

45 Joffe M, Robertson A. The potential contribution of increased vegetable and fruit consumption to health gain in the European Union. Public Health Nutrition 2001; 4: 893-901.

46 Tobias M. The Burden of Disease and Injury in New Zealand. Public Health Intelligence Occasional Bulletin No. 1. Wellington: New Zealand Ministry of Health, 2001.

47 Mathers C, Vos T, Stevenson C. The Burden of Disease and Injury in Australia. AIHW Catalogue No. PHE 17. Canberra: Australian Institute of Health and Welfare (AIHW), 1999

48 Vos T, Begg S. The Victorian Burden of Disease Study: Mortality. Melbourne: Public Health and Development Division, Victorian Government Department of Human Services, 1999.

49 World Health Organization (WHO) Regional Office for Europe. The First Action Plan for Food and Nutrition Policy. WHO European Region 200O-2005. Copenhagen: WHO Regional Office for Europe, 2000.

50 Doll R, Peto R. The Causes of Cancer. Oxford: University Press, 1981.

51 Doll R. The lessons of life. Keynote address to the nutrition and cancer conference. Cancer Research 1992; 52: 2024S-9S.

52 Browner WS, Westenhouse J, Tice J. What if Americans ate less fat? A quantitative estimate of the effect on mortality. Journal of the American Medical Association 1991; 265 : 285-91.

53 Willett WC. Will high-carbohydrate/low-fat diets reduce the risk of coronary heart disease?. Proceedings of the Society for Experimental Biology and Medicine 2000; 225: 187-90.

54 Willett WC. Diet, nutrition and avoidable cancer. Environmental Health Perspectives 1995; 103(Suppl.): 165-70.

55 Committee on Medical Aspects of Food Policy. Nutritional Aspects of the Development of Cancer. London: HMSO, 1998.

56 Riboli E, Decloitre F, Collet-Ribbing C. Alimentation et cancer: évaluation des données scientifique? Paris: Editions Techniques et Documentation, Lavoisier, 1996.

57 Papas AM, ed. Antioxidant Status, Diet, Nutrition, and Health. Boca Raton: FL: CRC Press, 1998.

58 Murray C, Lopez AD. On the comparable quantification of health risks: lessons from the Global Burden of Disease Study. Epidemiology 1999; 10: 594-605.

59 Greenland S, Rothman KJ. Measures of effect and measures of association. In: Rothman KJ, Greenland S, eds. Modern Epidemiology, 2nd ed. Philadelphia, PA: Lippincott-Raven Publishers, 1998; 47-66.

60 Ezzati M, Lopez AD, Rodgers A, Vander Hoorn S, Murray CJL and the Comparative Risk Assessment Collaborating Group. Selected major risk factors and global and regional burden of disease. Lancet 2002; 360: 1347-60.
61 Lock K, Pomerleau J, Causer L, McKee M. Global burden of disease due to low fruit and vegetable consumption. In: Ezzati M, Lopez AD, Rodgers A, Murray CJL, eds. Comparative Quantification of Health Risks: Global and Regional Burden of Disease Due to Selected Major Risk Factors. Geneva: WHO, 2003; in press.

62 European Commission. Improvement in Knowledge of Food Consumption with a View to Protection of Public Health by Means of Exchanges and Collaboration between Database Managers. Reports on Tasks for Scientific Cooperation, EUR 17528 (EN). Brussels: European Commission, 1997.

63 Bingham SA, Paul AA, Haraldsdottir J, Løken EB, Van Staveren WA. Methods of data collection at an individual level. In: Cameron ME, van Staveran WA, eds. Manual on Methodology for Food Consumption Studies. Oxford: Oxford University Press, 1988; 53-106.

64 Willett W, ed. Nutritional Epidemiology. Oxford: Oxford University Press, 1998.

65 Powles J, Day NE, Sanz MA, Bingham SA. Protective foods in winter and spring: a key to lower vascular mortality? Lancet 1996; 348: 898-9.

66 Terry P, Giovanucci E, Michels KB, Bergvist L, Hansen H, Holmberg L, et al. Fruit, vegetables, dietary fiber and risk of colorectal cancer. Journal of the National Cancer Institute 2001; 93: 525-33.

67 Law MR, Morris JK. By how much does fruit and vegetable consumption reduce the risk of ischaemic heart disease? European Journal of Clinical Nutrition 1998; 52: 549-56.

68 Egger M, Schneider M, Davey Smith G. Spurious precision? Meta-analysis of observational studies. British Medical Journal 1998; 316: 140-4.

69 Ness AR, Egger M, Davey Smith G. Meta-analysis seems to exclude benefit of vitamin C supplementation. British Medical Journal 1999; 319: 577.

70 Cameron ME, Van Staveren WA. Manual on Methodology for Food Consumption Studies. Oxford: Oxford University Press, 1988.

71 McKee M, Shkolnikov V, Leon DA. Alcohol is implicated in the fluctuations in cardiovascular disease in Russia since the 1980s. Annals of Epidemiology 2001; 11: 1-6.

72 Ness A, Egger M, Powles J. Fruit and vegetables and ischaemic heart disease: systematic review or misleading meta-analysis? European Journal of Clinical Nutrition 1999; 53: $900-2$

73 World Health Organization (WHO) Regional Office for Europe. Food and Health in Europe: A New Basis for Action; Copenhagen: WHO Regional Office for Europe, 2003; in press.

74 Gonzalez CA. Dietary patterns in Europe - preliminary results of dietary habits in the EPIC Study. European Prospective Investigation on Cancer and Nutrition. European Journal of Cancer Prevention 1997; 6: 125-6.

75 World Health Organization (WHO) Regional Office for Europe. Development of the First Food and Nutrition Action Plan for the European Region. Report of a WHO Consultation, Malta, 8-10 November 1999. Copenhagen: WHO Regional Office for Europe, 2000.

76 McColl K, Pomerleau J, Weill C, Oberlé D, Brodin M, Lefebvre A, et al. Health and Human Nutrition: Element for European Action. Collection Santé \& Société no. 10. Paris: Société Française de Santé Publique, 2000. 